\title{
The effects of interprofessional diabetes education on the knowledge of medical, dentistry and nursing students
}

\author{
Maja Račić ${ }^{1}$, Bojan N. Joksimović ${ }^{2}$, Smiljka Cicmil ${ }^{3}$, Srebrenka Kusmuk ${ }^{1}$, Nedeljka \\ Ivkovićs ${ }^{3}$ Natalija Hadživuković ${ }^{4}$, Milan Kulić ${ }^{2}$, Biljana Mijović ${ }^{1}$, Mirjana Mirićs, \\ Vedrana R. Joksimović ${ }^{1}$, Milena Dubravac ${ }^{1}$
}

${ }^{1}$ Department of Primary Health Care and Public Health, Faculty of Medicine Foča, University of East Sarajevo, Bosnia and Herzegovina, ${ }^{2}$ Department of Basic sciences, Faculty of Medicine Foča University of East Sarajevo, Bosnia and Herzegovina, ${ }^{3}$ Department of Oral Rehabilitation, Faculty of Medicine Foča University of East Sarajevo, Bosnia and Herzegovina, ${ }^{4}$ Department of Nursing, Faculty of Medicine Foča, University of East Sarajevo, Bosnia and Herzegovina ${ }^{5}$ Department of Pathological Physiology Medical Faculty of the University in Pristina with temporary seat in Kosovska Mitrovica, Kosovo, Serbia

\section{Correspondence: \\ joksimovic_bojan@yahoo.com \\ Tel.: +38765373507 \\ Fax.: + 38758210007}

Received: 31 August 2017

Accepted: 30 November 2017

Key words: Interprofessional education Diabetes mellitus - Professional role.

\begin{abstract}
Objectives. Interprofessional teamwork is best attained through education that promotes mutual trust and effective communication. The primary aim of the study was to evaluate the impact of interprofessional learning on knowledge about diabetes. Methods. The cross-sectional study included students of medicine, dentistry and nursing at the Faculty of Medicine Foča, Bosnia and Herzegovina. The students were randomly allocated into one of two groups. Group 1 attended an interprofessional course on diabetes while group 2 was divided into three subgroups and each of the subgroups attended an uniprofessional diabetes course. The measuring instrument used in the course in order to assess the participants' knowledge about diabetic care was a test containing multiple-choice questions about diabetes. The Interprofessional Questionnaire was used to explore the attitudes, views, values and beliefs of students regarding interprofessional education (IPE). Results. No statistically significant difference in total score on the test was found between the groups at baseline, but at follow-up the difference was highly statistically significant $(\mathrm{F}=10.87 ; \mathrm{p}=0.002)$. The students from Group 1 had better results (21.82 points), compared to Group 2 (18.77 points). The statistically significant difference was observed in mean values $(t=-3.997 ; \mathrm{p}=0.001)$, between Groups 1 and 2; the students from Group 1 obtained 20.42 points, which is considered to indicate a respectively positive self-assessment of communication and teamwork skills. However, Group 2 indicated a negative self-assessment of communication and teamwork skills. Conclusion. The findings suggest that IPE activities may provide health profession students with valuable collaborative learning opportunities.
\end{abstract}

\section{Introduction}

Each profession has distinct professionbased behavior, viewpoint, and values, even before commencing undergraduate training $(1,2)$. Prior work has found entrenched ingroup ratings of academic ability and professional competence among students across
10 professional and social care programs surveyed at the outset of their training; firstyear nursing, pharmacy, and medical students all perceive themselves as more "caring" than members of the other disciplines $(3,4)$. Such health-professional stereotypes can adversely impact teamwork and, ultimately, patient care $(5,6)$. 
West et al. (7) concluded that clear professional roles are essential, and that team members could benefit from a comprehensive understanding of both their own professional role and the professional roles of their colleagues. Damour and Oansen (8) concluded that educational efforts should be introduced early in the curriculum, prior to the developing of professional identities and the formation of stereotypes. Saroo et al. (9) argued that successful interprofessional training should take advantage of the students' psycho-sociological determinants, such as professional role behavior, hierarchy, and power relations. According to the Centre for the Advancement of Interprofessional Education (CAIPE), interprofessional learning involves "educators and learners from 2 or more health professions and their foundational disciplines who jointly create and foster a collaborative learning environment. The goal of these efforts is to develop knowledge, skills and attitudes that result in interprofessional team behaviors and competence" $(10,11)$.

Different studies noted that the students are not sufficiently exposed to interprofessional teamwork during their clinical training $(12,13)$. Aase et al. (14) found that theoretical lectures on interprofessional teamwork were not followed-up in clinical training, especially in nursing schools. Medical schools exposed their students to more interprofessional education (IPE), but, still they are not very compliant with the WHO recommendations, calling for strengthening interprofessional teamwork in educational programs (14). The reasons for this are partly because of faculty and students' attitudes (15).

On the other hand, diversity in the implementation of IPE has made it difficult to determine best practice models, optimal IPE delivery model or reliable measurement tools $(16,17)$. Examples of reliable measure- ment tools to measure IPE are Interdisciplinary Education Perception Scale (IEPS) and University of the West of England Entry Level Interprofessional Questionnaire (UWE-ELIQ) (18). It has been suggested that IPE courses should have defined the core competences as their curricular components (19). A comprehensive assessment of those competences is needed for effective medical and health care education programs. A clear differentiation between the identification of essential components (knowledge, skills, and attitudes) and of criteria to assess the behavioral performance of health care workers is crucial, as in the performance criteria several components are integrated or used in combination (20).

Numerous studies of the effectiveness on interprofessional education compared IPE to education in which the same professions were learning independently from each other $(21,22)$. The analyses suggested that IPE seemed to be more effective in relation to reaction and learning, with much less evidence of impact on behavior and results. Based on the findings from other studies evaluating the use of interprofessional education, the staff of Medical School Eastern Sarajevo decided to conduct an interprofessional course on diabetes. The lecturers focused on four interprofessional competency domains outlined by the Interprofessional Education Collaborative: ethics, roles and responsibilities, communication and teamwork.

The primary aim of the study was to evaluate the impact of interprofessional learning on knowledge about diabetes, the roles, and responsibilities of other health professions. The secondary aim was to analyze the attitudes, views, values and beliefs of health profession students who are learning together, regarding IPE, compared to the students who are learning independently from each other. 


\section{Methods}

\section{Data collection and participant characteristics}

The cross-sectional study was conducted during the winter semester at the Faculty of Medicine, University of East Sarajevo, Bosnia and Herzegovina, in January 2017. Participants were all students enrolled in sixth-year of medicine (29 students), fifthyear of dentistry (21 student) and third-year of nursing (16 students), as the teaching curricula for these years and study programs integrated obligatory lectures in diabetes. The list with students' names, provided by the Student Administrative Service, was torn into separate strips. The strips were put in a hat and were mixed. Each name was pulled out and put into one of two groups alternately. Group 1 attended interprofessional course on diabetes. Group 2 was divided into three subgroups: medical, dental and nursing.

\section{Intervention design}

The interprofessional diabetes course was designed to provide students with in-depth knowledge of diabetes mellitus. The course was a one-day mandatory class and consisted of four blocks. Block 1 focused didactically on the therapeutic management of Type 1 and Type 2 Diabetes, blood glucose monitoring, patient education and evidence-base for diabetes care and decision making in interprofessional practice. Block 2 didactics focused on the ethics, roles, responsibilities and scope of medical, dental and nursing practices, and introduced the characteristics of an effective team. Block 3 analyzed government strategies for diabetes and examined their benefits for practice within an interprofessional context and evaluated the physical, psycho-social and cultural impact of diabetes on the patient and family. The last block focused on a paper-based case scenario in which a newly established patient with diabetes was presented. The scenario incorporated the history provided by family practitioner. Students included in IPE were placed in eight mixed-profession teams, consisting of 3-4 medicine, 2-3 dentistry and 2 nursing students that remained together throughout the whole course.

After each didactic block, team members met to discuss personal values, teamwork, leadership, consensus building and the ability to identify and achieve joint goals in care for patients related to presented topic. Vision of team-working, decision making processes, shared responsibility for team actions, own role and the roles of others, role boundaries, team skills and knowledge were explored. At the end of course, each team reviewed the activities that occurred at the process of interprofessional learning.

The course content for group 2 was identical except for the interprofessional group work. Students received the same learning experience, but interaction with students of different health profession was lacking. Didactic blocks were handled by three faculty members, with background in family medicine, parodontology and nursing.

\section{The measuring instruments}

The measuring instrument used during the course to assess the participants' knowledge about diabetic care was a test containing multiple-choice questions about diabetes. The multiple-choice test contained 20 questions, divided into two scales, about diabetic patient care, with each question carrying between 1 to 4 points, and with the total score being 33 . The first subscale consisted of 13 questions about the general knowledge about diabetes (definition, diagnosis, screening, self-control, complication, treatment and care for diabetic patients). To explore if IPE contributes to nursing and medicine students' knowledge regarding oral health in 
diabetic patients, the second subscale consisted of 10 questions was also included. The test was distributed at the beginning of the course, and after completion of the course. The large amphitheater was provided to allow students to sit in every third seat and every second row. The students were assigned to specific seat, and seating arrangement was changed for follow-up test. To prevent cheating, mobile phone signals were blocked. Prior to the test, the principal researcher presented student behavior rules. The students were instructed to conduct themselves honestly. They were not permitted to ask the questions of invigilators (except in the case of ambiguities) or to copy someone else's answers. Four invigilators practiced constant observation, watching the students all the time. Test-taking time was 30 minutes long.

To explore the attitudes, views, values, and beliefs of study participants regarding IPE, the Interprofessional Questionnaire, based on the University of the West of England Entry Level Interprofessional Questionnaire (UWE-ELIQ) (23) was used. The Questionnaire included 33 multiple- choices questions, divided into 4 scales: interprofessional learning, communication and teamwork scale, interprofessional interaction and interprofessional relationships. The answers were rated according to Likert-type scale.

The Interprofessional Learning Scale assessed attitudes towards learning in an interprofessional setting, whilst the Interprofessional Interaction scale analyzed perceptions of other interprofessional colleagues and interactions. The perceptions of students' own relationships with colleagues were evaluated with the Interprofessional relationships scale. The answers were scored from 1 (strongly agree) to 5 (strongly disagree), the neutral point being included. The scores for these three scales were predetermined for the questionnaire, indicating positive ( 8 to 20 points), neutral (21 to
27 points) or negative (28 to 40 points) attitudes or perception.

The Communication and Teamwork Scale provided self-assessment of skills. The statements were scored from 1 (strongly agree) to 4 (strongly disagree). Positive selfassessment was defined as meeting expectation, and unsatisfactory communication/ teamwork skills were transmitted to negative self-assessment. The minimum score was 8 , maximum 32 . The score from $8-20$ represented positive, 21-25 neutral, and 26-32 negative self-assessment of skills. The reliability analysis was conducted by calculating a Cronbach's alpha coefficient and its value of 0.724 was found to be satisfactory.

\section{Ethical considerations}

The study is conducted with the approval of the Ethical Committee of the Medical Faculty of Foča, University of East Sarajevo, Bosnia and Herzegovina.

\section{Statistical analysis}

Statistical analyses were carried out using SPSS 20 (SPSS Inc., Chicago, IL, USA). The $p$ values of less than 0.05 were considered as statistically significant. Data were described using percentages, mean values, standard deviations, and frequency distributions. The Paired-Samples T test was used to compare mean values before and after intervention on students. ANOVA with repeated measures was used to show possible statistically significant differences between study programs and groups of students at baseline and at follow up. The independent $t$-test was used to show statistically significant differences between study programs and groups of students in mean values of the Interprofessional Questionnaire. To determine correlations between the knowledge of students and the IPE Questionnaire answers, we used Pearson's coefficient for correlations. 


\section{Results}

The study included 66 undergraduate students divided in two groups, first, interprofessional (Group 1) and second, uniprofessional (Group 2). Mean \pm SD age in study population was $23.1 \pm 2.8$ years, and $57.6 \%$ of participants were female. Majority of respondents in both groups study medicine (44.2\%), 31.8\% dentistry and $25.8 \%$ nursing school. The statistically significant differences between baseline and follow-up knowledge about diabetes $(\mathrm{t}=-8.166 ; \mathrm{p}=0.001)$ and impact of diabetes on oral health were found (Table 1).

Gradient improvement of knowledge was detected in both groups, but at followup, the scores were significantly higher among interprofessional group of students (Table 2).

Table 3 shows the comparisons of mean values of test scores between the students of medicine, nursing and dentistry. Although baseline and follow up general knowledge on diabetes were the greatest among medicine, and oral health among dentistry students, significant differences in total score at follow-up were not found $(\mathrm{F}=0.179, \mathrm{p}=0.836$ ).

The Communication and Teamwork scale was used to evaluate students' communication and teamwork skills. Self-assessment of skills in interprofessional group was positive, and in uniprofessional group negative $(\mathrm{t}=-3.997 ; \mathrm{p}=0.001)$. The perceptions of students' own relationships were positive in both groups, conversely, attitudes towards learning in an interprofessional setting and perceptions of interprofessional interactions were positive in group 1 and neutral in group 2 (Table 4).

Dentistry students reported positive selfassessment of communication and teamwork skills (20.38 points), compared to medical (26.03 points) and nursing students (27.23 points), whose self-assessment was neutral and negative, respectively $(\mathrm{t}=-3.270$; $\mathrm{p}=0.005)$. The attitude of medicine students

Table 1 Comparisons of test score mean values before and after the course

\begin{tabular}{lllll}
\hline \multirow{2}{*}{ Test score } & \multicolumn{2}{l}{ Mean values $( \pm$ SD) of test scores } & \multirow{2}{*}{ t - test } & $\mathrm{p}$ \\
\cline { 2 - 4 } & \multicolumn{1}{l}{ Baseline } & Follow up & -8.166 & 0.001 \\
\hline Subscale 1 & $5.83(2.47)$ & $9.13(3.80)$ & -11.317 & 0.001 \\
\hline Subscale 2 & $7.54(2.03)$ & $11.34(2.78)$ & -12.510 & 0.001 \\
\hline Total score & $13.37(2.76)$ & $20.39(4.30)$ & \\
\hline
\end{tabular}

Table 2 Comparisons of the test score mean values between interprofessional and uniprofessional groups at baseline and at follow up

\begin{tabular}{cllll}
\hline \multirow{2}{*}{ Test score } & \multicolumn{2}{l}{ Mean values $( \pm$ SD) of test scores } & t - test & $p$ \\
\cline { 2 - 4 } & Group 1 & Group 2 & & \\
\hline Subscale 1 & & & 0.246 & 0.622 \\
\hline Baseline & $6.11(2.31)$ & $7.51(2.64)$ & 7.04 & 0.010 \\
Follow up & $10.31(3.66)$ & $7.80(3.54)$ & & 0.009 \\
\hline Subscale 2 & & & 7.25 & 0.043 \\
\hline Baseline & $7.08(1.54)$ & $10.06(2.39)$ & 4.26 & 0.188 \\
Follow up & $11.68(1.23)$ & & & 0.002 \\
\hline Total score & & $13.58(3.05)$ & 1.77 & 10.87 \\
\hline Baseline & $13.20(2.51)$ & $18.77(3.41)$ & & \\
\hline Follow up & $21.82(4.54)$ & & & \\
\hline
\end{tabular}


Table 3 Comparisons of the test scores mean values according to the study programs at baseline and at follow up

\begin{tabular}{|c|c|c|c|c|c|}
\hline \multirow{2}{*}{ Test score } & \multicolumn{3}{|c|}{ Mean values $( \pm S D$ ) of test scores } & \multirow{2}{*}{$\mathrm{F}$} & \multirow{2}{*}{$\mathrm{p}$} \\
\hline & Medical students & Dentistry students & Nursing students & & \\
\hline \multicolumn{6}{|l|}{ Subscale 1} \\
\hline Baseline & $7.64(1.70)$ & $3.28(1.67)$ & $6.00(1.45)$ & 23.22 & 0.001 \\
\hline Follow up & $11.21(2.42)$ & $5.95(3.90)$ & $9.64(2.89)$ & 5.073 & 0.009 \\
\hline \multicolumn{6}{|l|}{ Subscale 2} \\
\hline Baseline & $7.57(1.16)$ & $9.09(1.84)$ & $5.58(1.73)$ & 15.10 & 0.001 \\
\hline Follow up & $10.32(2.40)$ & $14(1.76)$ & $9.76(1.04)$ & 15.48 & 0.001 \\
\hline \multicolumn{6}{|l|}{ Total score } \\
\hline Baseline & $15.21(2.25)$ & $12.38(2.51)$ & $11.58(2.00)$ & 14.57 & 0.001 \\
\hline Follow up & $21.32(4.75)$ & $19.95(3.72)$ & $19.41(4.12)$ & 0.179 & 0.836 \\
\hline
\end{tabular}

$\mathrm{F}=$ Variation between sample means, ANOVA.

Table 4 Comparisons of mean values of Interprofessional Questionnaire in three study programs

\begin{tabular}{|c|c|c|c|c|}
\hline \multirow{3}{*}{$\begin{array}{l}\text { Groups } \\
\text { of students }\end{array}$} & \multicolumn{4}{|c|}{ Interprofessional Questionnaire scales } \\
\hline & CETS & ILS & IIS & IRRS \\
\hline & Mean (SD) & Mean (SD) & Mean (SD) & Mean (SD) \\
\hline Group 1 & $20.42(5.12)$ & $18.77(9.58)$ & $20.25(5.72)$ & $16.65(7.17)$ \\
\hline Group 2 & $28.06(7.88)$ & $21.54(8.84)$ & $22.67(4.74)$ & $18.45(7.81)$ \\
\hline$t-$ test/p & $-3.997 / 0.001$ & $-1,128 / 0.226$ & $-1.857 / 0.068$ & $-0.972 / 0.335$ \\
\hline Medical & $26.03(8.01)$ & $22.96(9,97)$ & $21.60(5.46)$ & $18.85(7.90)$ \\
\hline Dentistry & $20.38(3.82)$ & $18.47(5.92)$ & $20.04(4.37)$ & $16.71(4.86)$ \\
\hline Nursing & $27.23(7,28)$ & $17.29(10.72)$ & $22.7(6.33)$ & $16.41(7.59)$ \\
\hline $\mathrm{t}-$ test/p & $3.270 / 0.005$ & 1.982 / 0.058 & $1.115 / 0.271$ & $1.019 / 0.314$ \\
\hline
\end{tabular}

CETS=Communication, Ethics and Teamwork scale; ILS=Interprofessional Learning scale; IIS=Interprofessional Interaction Scale; IRRS=Interprofessional Roles and Responsibilities Scale.

Table 5 Correlation between students' knowledge and Interprofessional Questionnaire scales

\begin{tabular}{lllll}
\hline \multirow{2}{*}{ Test score } & \multicolumn{4}{l}{ Interprofessional Questionnaire Scales } \\
\cline { 2 - 5 } & \multicolumn{1}{l}{ CETS } & ILS & IIS & IRRS \\
\cline { 2 - 5 } & $\mathrm{r} / \mathrm{p}$ & $\mathrm{r} / \mathrm{p}$ & $\mathrm{r} / \mathrm{p}$ & $\mathrm{r} / \mathrm{p}$ \\
\hline Subscale 1 & $0.084 / 0.501$ & $0.013 / 0.919$ & $0.030 / 0.813$ & $-0.047 / 0.705$ \\
Subscale 2 & $-0.673 / 0.001$ & $-0.284 / 0.021$ & $-0.397 / 0.001$ & $-0.247 / 0.046$ \\
\hline Total score & $-0.327 / 0.007$ & $-.137 / 0.274$ & $-0.189 / 0.128$ & $-0.175 / 0.159$ \\
\hline
\end{tabular}

CETS= Communication, Ethics and Teamwork scale; ILS=Interprofessional Learning scale; IIS=Interprofessional Interaction Scale; IRRS=Interprofessional Roles and Responsibilities Scale; $r=$ correlation coefficient.

related to inteprofessional learning was neutral contrary to (22.96) positive attitudes of dentistry (18.47) and nursing students (17.29). All three groups had a positive perception about interprofessional interaction and their own interprofessional relation- ships. However, statistical significant differences in attitudes and perceptions by study program and intervention were not found. The correlation between test subscales and Interprofessional Questionnaire' scales are shown in Table 5. 
Anecdotal comments included Group 1 students remarking how much more informed they were now about the role of health care of professions other than their own, and that there should be more of such learning and teaching activities organized during undergraduate studies

\section{Discussion}

To evaluate the health profession students' skills, perception and attitudes regarding IPE, the course on diabetes was carried out. The current study showed that health profession students who participated in IPE course had greater overall knowledge of diabetes as well as more positive assessment of their communication and teamwork skill compared to the students involved in uniprofessional course. The findings are in line with other studies showing the influence of bringing different health professions together to learn on achieving better results and interprofessional collaboration (23-25).

The literature suggests that implementation of IPE into undergraduate curricula could increase the likelihood of future physicians, nurses and dentists engaging in a communicative and team member behavior that promotes and improves the model of multidisciplinary, patient-centered care. Helping students form, and successfully integrate, their professional selves into their multiple identities is a fundamental of medical education $(26,27)$. Albeit the most students in IPE group rated their communication and teamwork skills positively, a significant difference was found between self-assessed skills of different health profession students. Nursing students had more negative opinion compared with neutral self-assessment of medicine and positive view of dentistry students. The quantity of structured interpersonal learning experiences was but few at Faculty of Medicine Foča, and this was the first course in the medicine, nursing and dentistry undergraduate curricula addressing IPE. As curricula are traditional, understanding of others health professions' roles is limited, nurses being seen as proximate, caring aids to physicians, physicians as main care providers for diabetic patients, and dentists as a profession taking care of oral health only. Available data indicate that collaboration readiness and specifically higher levels of confidence in personal skills could be improved by engaging all health profession students in IPE $(27,28)$. IPE sustains augmented confidence relating to students' skills and positive attitudes toward interprofessional roles and responsibilities (29).

Differences in attitudes toward interprofessional learning, roles and interaction were not found among the students participating in IPE and non-IPE course. However, the students exposed to IPE were more favorably inclined towards interprofessional learning in addition to dentistry and nursing students generally, what corroborates previous studies (30). They held counteractive opinions about interprofessional interaction. In agreement with prior research (31, 32) all students reported improvement in understanding the roles of other health professionals in the patient care and challenges of learning in interprofessional teams as this was the first time for all students, regardless the study program and intervention, to have the opportunity to attend lectures presented by the professors with different expertise.

An improvement in diabetes knowledge level was identified among all three professions, medical, dentistry and nursing. There was a statistically significant difference in baseline knowledge. As expected, medical students had the highest score in general knowledge and dentistry students in oral health due to the previous training in the specific areas. Observing the subscales responses, the scores per group notably increased with the ratio between the professions being stable, but the difference in to- 
tal scores by study program was not found. Both interventions included contents new to students, involving multidisciplinary clinical scenario that might have allowed increased understanding of diabetes and its oral-systemic connections (33). IPE course particularly strengthened the knowledge of the nursing students who started with low scores. Sequential with the findings of others, the authors of the current study believe it is possible that integrating IPE learning activities into undergraduate health profession curricula, within the context of a relevant topic like diabetes management, may augment students' learning abilities and improve their collaboration related competences $(29,34,35)$.

Creating the IPE courses requires cooperation from deans, administrators and faculty members. Curricula in each discipline should offer sufficient opportunities for students to first interact, both formally and informally, with their own members, and to explore and even challenge accepted frameworks of established roles $(36,37)$.

\section{Limitations of the study}

The current study has several limitations. The findings could be specific to University of East Sarajevo and didactic approach of the faculty, which was not necessarily the same as at the other faculties of medicine in Bosnia and Herzegovina. Knowledge, attitudes and perception were assessed at one point in time. The study was based on the self-assessment, therefore subjectivity and accountability need be considered. Although this study demonstrates promising findings, it is preliminary, so replication of the study longitudinally, throughout study years, analyzing the comparison of a change in attitudes, and including the higher number of participants should be set up at same and other faculties of medicine in the country. Future research is needed to examine whether IPE could result in a breakdown of negative stereotypes over time and if so, what type of IPE intervention would be the most effective.

\section{Conclusion}

The findings suggest that interprofessional education activities may provide health profession students with valuable collaborative learning opportunities in addition to improving specific clinical knowledge, level of confidence in own skills and positive attitude conducive to collaboration with other health professionals. In order to prepare the health professional students for interprofessional collaborative practice following graduation, different IPE interventions are needed. Further longitudinal, multi-site studies exploring the impact of interprofessional learning on knowledge, attitudes and perceptions of students are requisite.

\section{What is already known on this topic}

Interprofessional teamwork is best attained through education that promotes mutual trust and effective communication. According to the Centre for the Advancement of Interprofessional Education (CAIPE), interprofessional learning involves educators and learners from 2 or more health professions and their foundational disciplines who jointly create and foster a collaborative learning environment. The goal of these efforts is to develop knowledge, skills and attitudes that result in interprofessional team behaviors and competence. Health professionals as team members could benefit from a comprehensive understanding of both their own professional role and the professional roles of their colleagues.

\section{What this study adds}

Interprofessional education activities may provide health profession students with valuable collaborative learning opportunities in addition to improving specific clinical knowledge, level of confidence in own skills and positive attitude conducive to collaboration with other health professionals. In this line, we evaluated impact of interprofessional learning on knowledge about diabetes among medical, dentistry and nursing students. We also explored the attitudes, views, values and beliefs of students regarding interprofessional education.

Authors' contributions: Conception and design: MR, BNJ, SC, SK, NI, NH, MK, BM, MM, VRJ and $\mathrm{MD}$; Acquisition, analysis and interpretation of data: 
MR, BNJ, SC, SK, NI, NH, MK, BM, MM, VRJ and MD; Drafting the article: MR, BNJ, SC, SK, NI, NH, MK, BM, MM, VRJ and MD; Revising it critically for important intellectual content: MR, BNJ, SC, SK, NI, NH, MK, BM, MM, VRJ and MD; Approved final version of the manuscript: MR, BNJ, SC, SK, NI, NH, $\mathrm{MK}, \mathrm{BM}, \mathrm{MM}, \mathrm{VRJ}$ and MD.

\section{References}

1. Rudland J, Mires GJ. Characteristics of doctors and nurses as perceived by students entering medical school: Implications for shared teaching. Med Educ. 2005;39(5):448-55.

2. Harsburgh M, Perkins R, Coyle B, Degeling P. The professional subcultures of students entering medicine, nursing and pharmacy programmes. J Interprof Care. 2006;20(4):425-31.

3. Hean S, Macleod Clark J, Adams K, Humphris D, Lathlean J. Being seen by others as we see ourselves: the congruence beteewn the ingroup and outgroup perceptions of health and social care students. Learn Health Soc Care. 2006;5(1):10-22.

4. Hawkes G, Nunney I, Lindqvist S. Caring for attitudes as a means of caring for patients - improving medical, pharmacy, and nursing student's attitudes to each other's professions by engaging them in interprofessional learning. Med Teach. 2013;35(7):1302-8.

5. Wilbur K, Kelly I. Interprofessional impressions among nursing and pharmacy students: a qualitative study to inform interprofessional education initiatives. BMC Med Edu. 2015;15:53.

6. Koffel C, Burke KG, McGuinn K, Miltner RS. Integration of Quality and Safety Education for Nurses Into Practice: Academic-Practice Partnership's Role. Nurse Educ. 2017;42(5S Suppl 1):S49-S52.

7. West M, Markiowicsz L. Building Team-Based Working. Cornwall: The British Society and Blackwell Publishing Ltd; 2004.

8. D'Amour D, Oandasan I. Interprofessionality as the field of interprofessional practice and interprofessional education: An emerging concept. J Interprof Care. 2005;19 Suppl 1:8-20.

9. Sharma S, Boet S, Kitto S, Reeves S. Interprofessional simulated learning: the need for 'sociological fidelity’. J Interprof Care. 2011;25(2):81-3.

10. Center for Advancement of Interprofessional Education (CAIPE) [cited 2017 Oct 21]. Available from: http://www.caipe.org.uk.

11. Buring SM, Bhushan A, Broeseker A, Conway S, Duncan-Hewitt W, Hansen L, et al. Interprofessional Education: Definitions, Student Compe- tencies, and Guidelines for Implementation. Am J Pharm Educ. 2009;73(4):59.

12. Bjorke G. Collaboration across professional boundaries [in Norwegian]. HiO-Report No 1. Oslo: Hogskolen i Oslo; 2009.

13. Almås S, Barr H. Common curricula in Norway: Differential implementation and differential outcomes in undergraduate health and social care education. J Interprof Care. 2008;22(6):650-7.

14. Aase I, Aase K, Dieckmann P. Teaching interprofessional teamwork in medical and nursing education in Norway: A content analysis. J Interprof Care. 2013;27(3):238-45.

15. Clark PG. Examining the interface between interprofessional practice and education: Lessons learned from Norway for promoting teamwork. J Interprof Care. 2011;25(1):26-32.

16. Thistlethwaite J. Interprofessional education: A review of context learning and the research agenda. J Interprof Care. 2012;46(1):58-70.

17. Reeves S, Zwarenstein M, Goldmnn J, Barr H, Freeth D, Koppel I, et al. The effectiveness of interprofessional education: Key findings from a new systematic review. J Interprof Care. 2010;24(3):230-41.

18. Simko LC, Rhodes DC, McGinnis KA, Fiedor J. Students' perspectives on interprofessional teamwork before and after an interprofessional pain education course. Am J Pharm Educ. 2017;81(6):104.

19. Interprofessional Education Collaborative Expert Panel. Core competencies for interprofessional collaborative practice: report of an expert panel. Washington, DC: Interprofessional Education Collaborative; 2011.

20. Vyt A. Interprofessional and transdisciplinary teamwork in health care. Diabetes Metab Res Rev. 2008;24 Suppl 1:S106-9.

21. Vary PM, Lash J, Brown SS, Porter AG, Trinkle D, Garber JS, et al. Collaborative Practice Education: The Effect of an Interprofessional Teamwork Course on Students' Knowledge and Skills. Med Sci Educ. 2013;23(Suppl 3):494-501.

22. Zwarenstein M, Reeves S, Perrier L. Effectiveness of pre-licensure interprofessional education and post-licensure collaborative interventions. J Interprof Care. 2005;19 Suppl 1:148-65.

23. Freeth D, Reeves S, Koppel I, Hammick M, Barr $H$. Evaluating interprofessional education: a selfhelp guide. London: Higher Health Educational Academy Health Science and Practice Network/ CAIPE; 2005.

24. McFadyen AK, Webster VS, Maclaren WM. The test-retest reliability of a revised version of the 
Readiness for Interprofessional Learning Scale (RIPLS). J Interprof Care. 2006;20(6):633-9.

25. Evans JL, Henderson A, Johnson NW. Interprofessional learning enhances knowledge of roles but is less able to shift attitudes: a case study from dental education. Eur J Dent Educ. 2012;16(4):239-45.

26. Pollard KC, Miers ME, Gilchrist M. Collaborative learning for collaborative working? Initial findings from a longitudinal study of health and social care students. Health Soc Care Community. 2004;12(4):346-58.

27. Anderson ES, Thorpe LN. Early interprofessional interactions: does student age matter? J Interprof Care. 2008;22(3):263-82.

28. Ruebling I, Pole D, Breitbach AP, Frager A, Kettenbach G, Westhus N, et al. A comparison of student attitudes and perceptions before and after an introductory interprofessional education experience. J Interprof Care. 2014;28(1):23-7.

29. Pollard KC, Miers ME. From students to professionals: results of a longitudinal study of attitudes to pre-qualifying collaborative learning and working in health and social care in the United Kingdom. J Interprof Care. 2008;22(4):399-416.

30. Gould K, Day KH, Barton AT. Changing student attitudes through interaction: Findings from an interprofessional workshop. J Interprof Care. 2017;31(4):540-2.

31. Reeves SA, Denault D, Huntington JT, Ogrinc G, Southard DR, Vebell R. Learning to Overcome Hi- erarchical Pressures to Achieve Safer Patient Care: An Interprofessional Simulation for Nursing, Medical, and Physician Assistant Students. Nurse Educ. 2017;42(5S Suppl 1):S27-31.

32. Anders PL, Scherer YK, Hatton M, Antonson D, Austin-Ketch T, Campbell-Heider N. Using Standardized Patients to Teach Interprofessional Competencies to Dental Students. J Dent Educ. 2016;80(1):65-72.

33. Darlow B, Coleman K, McKinlay E, Donovan S, Beckingsale L, Gray B, et al. The positive impact of interprofessional education: a controlled trial to evaluate a programme for health professional students. BMC Med Educ. 2015;15:98.

34. Goldie J. The formation of professional identity in medical students: considerations for educators. Med Teach. 2012;34(9):e641-8.

35. Pollard K, Miers ME, Gilchrist M. Second year scepticism: pre-qualifying health and social care students' midpoint self-assessment, attitudes and perceptions concerning interprofessional learning and working. J Interprof Care. 2005;19(3):251-68.

36. Wilbur K, Hasnani-Samnani Z, Kelly I. Interprofessional Education Activity Among Undergraduate Nursing and Pharmacy Students in the Middle East. Nurse Educ. 2015;40(4):163-4.

37. Luebbers EL, Dolansky MA, Vehovec A, Petty G. Implementation and evaluation of a communitybased interprofessional learning activity. J Interprof Care. 2017;31(1):91-7. 